\title{
Potential Use of Communications and Project Management Systems in Remote Construction Projects: The Case of Saudi Electric Company
}

\author{
Bhzad Sidawi \\ Assistant professor, Department of Architecture, University of Dammam, Saudi Arabia, E-mail: Bsidawi@ud.edu.sa
}

Project Management

Received August 10, 2011; received revision September 13, 2011; accepted October 22, 2011

Available online November 10, 2011

\begin{abstract}
Remote projects have their unique problems that are caused mainly by the remoteness of the project itself thus the loose control over management. This is due to a number of reasons such as lack of human resources and infrastructure. Research studies that were undertaken worldwide - regarding this issue- has highlighted few unique management problems. The aim of this paper is to investigate how far the IT tools would help in managing remote construction projects in the Kingdom of Saudi Arabia (KSA). Due to the lack of previous research regarding remote projects within the Gulf region and the KSA, a pilot study was conducted in 2009 to define and test the wording of questions that are part of the main survey. The main survey was undertaken on Saudi Electric Company (SEC). The study found that IT systems and tools have the potential but this potential is hindered by a number of technical, managerial, staff factors. Therefore, successful application of IT systems would require changes to the present management settings at various levels. This would ensure that the SEC is capable of achieving the full benefit from using these advanced systems.
\end{abstract}

Keywords: Mobile systems, web-based project management systems, virtual management.

\section{Introduction}

Project management aim is to efficiently and effectively meet unique goals that add value using available resources (Ko, 2011) and to achieve this aim rapid and steps were undertaken during the past few decades to improve the project-management practices and systems. However, there is still a number of negative issues still affects management of construction projects. These issues include use of inappropriate tools and systems for communication, coordination, and management. For example, Yang et al. (2007) suggest that intense need for project information and effective communications by the project team cannot be met by traditional communications and information management systems since these systems have shortcomings and are incapable of fulfilling project duties and objectives. One of these shortcomings is that traditional systems provide limited access to information, which is considered one of the key barriers to successful project management practices (Vadhavkar et al., 2002; Pena-mora et al., 2009). Recent studies by the Stichiting Bouw Research center in the Netherlands (2000) indicate that $6 \%$ to $7 \%$ of contract expenses are due to failures. Many of these failures are caused by inadequate organization and management of the construction process (e.g., a weak coordination of processes and uncertainty about available information) (Wamelink et al., 2002). These shortcomings brought about radical changes to traditional project management and communications methods such that new concepts and methods for managing projects have been invented. One of these concepts is the golden triangle, a concept that initially referred to quality, time, and cost but now extends to include sustainability, project team and stakeholder satisfaction, and health and safety issues. Communications and Project Management Systems (CPMS) such as mobile and Web-based Project Management Systems (WPMS) that use wireless, satellite, Internet-based, or mobile tools and networks have helped - to a certain degree construction industry firms manage the increasing complexity of construction projects. They have also helped fulfill project objectives such as quality, scope, time, and cost.

Remote construction projects exist in many regions throughout the world such as the Sahara desert, Antarctic regions, the Arabian Peninsula desert, etc. The dilemma in managing remote projects is highlighted by Deng et al. (2001), Kestle and London (2002, 2003), Kestle (2009), McAnulty and Baroudi (2010), and Thorpe (2000). These authors point out that a project's remoteness causes distinctive management problems. In the KSA, Saudi Electric Company (SEC) engages in a number of remote construction projects. These projects are of different sizes and range from electric power plants to warehouses and customer service blocks. They are in remote locations with rough terrain such as mountains and deserts and operate in undeveloped and environmentally sensitive regions. They 
are far from the supervision team office, the contractor's office, and major urban concentrations. During construction, all project parties experience countless difficulties and cumbersome management problems. These potential problems negatively affect project quality and cause substantial delays and increases in costs. This research investigates remote projects of SEC as a case study. Case study research provides in-depth investigation of the research problem and is used to explore causation to find underlying principles (Shepard and Greene, 2003; Yin, 2009).

Due to the lack of previous research regarding remote projects within the Gulf region and the KSA, a pilot study was conducted in 2009 to define and test the wording of questions that are part of the main survey and to establish foundations for the main survey. Many researchers such as Morse (1991) and Oppenheim (1992) recommend this approach. Thus, the primary survey was launched in mid2009 to find out the type of management and communication tools in use and the impact of remoteness represented by the impact of delay in making decisions on project performance and process. It explored whether use of CPMS helps SEC improve management of remote projects and, thus, reduces delays and avoids unnecessary costs. Simple statistical tools such as the Percentage and the Mean were used to analyze the data. The study however is limited to SEC's remote sites whereas SEC's supervision team members do not live on these sites.

\section{Review of the Current Use of CPMS}

Some of a remote project management's problems can be avoided if a CPMS were used. These systems include WPMS and mobile systems that feature mobile tools, personal digital assistants (PDA), wearable computers, wireless tools, and other technologies. These systems possess the capability to improve communications between project team members and enable teams to share information and quickly solve problems. They improve team members' ability to manage time and costs (Charoenngam et al., 2004). Davidson and Moshini (1990) and Bowden (2005) state that construction costs can be reduced by $25 \%$ through efficient transfer of information between the construction teams; that transfer can be achieved through CPMS. Ahuja et al. (2010) suggest that adoption of Information Communication Technology (ICT) enables effective communication between dispersed project team members but argues that strategic adoption of ICT (i.e. by a number of organizations involved in the construction process) requires that all supply chain members follow accepted methods of communication or protocols. This enables them to grasp effectively the IT benefits (Ahuja et al., 2009).

Alshawi and Ingirige (2003) and Stewart and Mohamed (2004) identify the following benefits of using WPMS: productivity enhancement of communication between project participants, reduction in project delays, heightened awareness of project issues among all parties, and ease of access to and retrieval of project information. Other advantages include: avoiding delays due to the arrival of updated drawings and documents, reducing visits to sites and travelling time to meetings, avoiding drawing mistakes, reducing time and money spent on disputes, sharing and exchanging project information, automating repetitive routine processes, and eliminating paper reports (2003). Thomas et al. (2003) discuss how WPMS - from the point of view of selecting contractors - helps project managers boost contractor performance and confidence by minimizing subjectivity and eliminating the potential for corrupt practices. This improves competitiveness through increased awareness of competitors' strengths and weaknesses and nurtures mutual trust in the exchange of sensitive information such as performance data. Nitithamyong and Skibniewski (2004, 2006) suggest that benefits of using WPMS can be categorized into four main areas. These categories include cost reduction and time saving, enhancement of communications and collaboration, improvement of productivity and partnership, and support of e-commerce and the customer.

A number of researchers anticipate that WPMS will replace traditional project management methods (Becerik, 2005; Zou and Roslan, 2005) and these methods are drivers of WPMS adoption. Several aspects support this claim including increased competitive pressures, expectations of revenue growth, the ability to compete globally, and the desire to reengineer the business to respond to market challenges (Nitithamyong and Skibniewski, 2006).

Leskinen (2006, 2008) argues that it is difficult to make direct assessment of which mobile systems would benefit the construction industry. The most important intangible benefits include improving customer service, gaining a competitive advantage, acquiring more timely management information, supporting core business functions, avoiding competitive disadvantages, improving management information, improving product quality, improving internal communication, implementing changes through innovation, improving external communication, and enhancing the jobs of employees.

Thorpe (2000) points out that the Online Remote Construction Management (ORCM) process has the potential to be useful to remote construction sites. He mentions that the implementation of ORCM technology should take into account equipment-related and logistical difficulties - particularly on the remote site; access to the Internet, which can be slow or unreliable; legal issues regarding use of electronic communications; cultural issues such as staff reluctance to change existing practices; ORCM systems implementation expenses; and the need for staff training.

Despite fast developments in IT and the creation of many IT applications for the construction industry, some issues still hinder the applicability of these systems to construction project management. There is a problem with regard to the diffusion of IT in the construction industry and the absorption of IT into work practices. This includes the level of strategic IT investment by construction industry firms (Alshawi et al., 2009). Other barriers include IT technical shortages, deployment of the system on an ad hoc basis, isolated project management practices, and costly systems (Alshawi and Ingirige, 2003; Nuria, 2005; Leskinen, 2006, 2008). Al Omairi and Sidawi (2010) found several barriers to the implementation of WPMS at Royal Commission of Jubail, KSA including staff resistance to change work methodology and processes, low levels of IT infrastructure of the organization and other parties, low computing proficiency levels of senior management and staff, concern for major investment without guarantee of success and/or returns, and preference for old-style paper-based/existing management protocols. 
Although there are barriers to IT adoption, the literature suggests that CPMS can impact project management practices positively. This research explores whether it would have similar effects on the management practices of remote projects. The following sections discuss remote construction site challenges and whether CPMS are capable of overcoming these problems.

\section{Review of Current Remote Projects Management Practices}

The dilemma of managing remote projects is highlighted by Deng et al. (2001), who mentions that the extensive physical distance between project participants, sometimes extending over national boundaries, is the primary cause of delays in decision making. The project team has to not only tackle traditional management problems but those that specifically occur as a result of the remote locations of these often environmentally sensitive sites (Kestle, 2009; Kestle and London, 2002, 2003). These sites are often far from logistic support and suffer a continuous shortage of materials and specialized labor (Kestle and London, 2002, 2003). Kestle (2009) investigated the management problems of remote project through two case studies: one a humanitarian project in West Darfur, Al Sudan and the other a drilling project of a scientific expedition in the Antarctic region. Kestle (2009) reports lack of project preplanning, certainty, and/or clarity concerning project process integration. There were also misinterpretations and miscommunications of project results and needs issues. A centralized decision-making process and lack of delegated authority to field personnel often hindered progress and communications at critical emergency response and recovery stages.

Kestle and London (2002) suggest a framework for the design management of remote sites. The framework emphasizes the following management functions:

- Serving:

Remote management involves more serving than simply leading;

\section{- Controlling}

Measurement and correction of team member performance and site activities on a daily basis;

\section{- Organizing:}

The organizational structure should establish a formal system of roles that people can perform and be supported by to accomplish the enterprise's objectives. The key factors for the management of remote sites are value generation, knowledge integration, process integration, and timely decision-making. Project teams located at disperse sites and that communicate and share recourses electronically are virtual teams; their organization is defined as a virtual organization. Virtual organizations generally tend to decentralize management. The traditional and hierarchical management structure changes to a more open, interactive, collaborative, and network structure (Turban et al., 1996). A crucial aspect of remote project success depends on effective sharing of knowledge and information among the different people and the building of trust among remote project teams (Uden and Naaranoja, 2007); and

\section{- Economizing:}

Management's performance should be economical, emphasizing effective action, efficient organization, optimal planning, and human-centered control with expertise service. The overall objective is cooperation to derive maximum benefit for the enterprise.

McAnulty and Baroudi (2010) conducted a survey of top and mid-tier construction contractors with experience in remote construction projects in Australia. They found that contractors experience difficulty attracting and retaining skilled workers; working in remote locations has a negative impact on an employee's family life. It is difficult to procure and access materials and equipment in remote areas and severe climatic factors in remote areas have a negative impact on productivity. There is lack of infrastructure and communications. The researchers suggest a number of possible solutions such as the need for appropriate material management systems and design cost information specifically for remote construction works. They recommend that unique types of costing issues should be included in the project's cost estimation; these include: mobilization/demobilization, accommodation, inclement weather downtime, site allowances, delivery, and productivity.

\section{SEC's Remote Project Management Practices and Systems Shortages}

In KSA, SEC has a number of remote construction projects. The construction process of these projects is divided into the following stages: site work; concrete work, masonry work, insulation materials for heat and humidity work, openings (e.g. doors and windows) work, finishing work (e.g. walls, ceilings, and floors), mechanical work (e.g. plumbing, air conditioning, and fire protection), electrical work, and telecommunications and computer work. SEC adopts a management methodology for remote projects similar to those of traditional projects. A pilot study was conducted in 2009 to find out more about management problems. It examined three projects' archives, questioned several project engineers/supervisors at SEC's regional office, and included a visit to one of the remote sites. The pilot revealed the following issues:

- Long travel times of four or more hours during round trips exhaust the supervisors, especially during extreme hot weather. Due to staff shortages, supervisors are overloaded with responsibilities; each has two or more remote sites to inspect. These problems sometimes force the supervisor to postpone necessary site visits. Unsupervised contractors seize this opportunity to make changes to construction plans and use improper construction materials and inadequate construction systems to cut costs. The result is poorer quality construction.

- Analysis of three projects' archives showed that a 30\% decrease in the number of visits to the site is associated with an increase in a project's costs by about $30 \%$ and an increase in a project's estimated duration and quality by about 20.

- Contractors are reluctant to undertake remote projects due to unpredictable increases in costs of labor, materials, transportation, and unforeseen circumstances. They are also concerned with unavailability of basic services for 
laborers such as housing, services, roads, etc. These factors sharply reduce the contractor's profit margins.

- There is a lack of contractor commitment to the project schedule due to the difficulties that they usually experience in providing skilled labor, transportation, etc.

- Lack of construction materials forces contractors to leave the project site regularly to procure them. This absence makes the sites vulnerable to thefts and records show that there were several cases of materials and equipment thefts.

- Government authorities responsible for granting permissions are far from the project site. The remoteness keeps government officers from making frequent visits to the site to perform necessary inspections and grant permissions.

- In some remote areas, the initial survey of the project site by SEC surveyors showed no definite owner of a specific plot of land. Thus, the SEC would possess the land and a budget was allocated for the project. Afterwards, a claim of ownership by a citizen (supported by the Sheikh [head] of one of the local tribes) would raise legal conflicts over land ownership and cause substantial delays to the project or even halt the project until the legal dispute was resolved.

- Delivery of materials and equipment is constrained by road/highway regulations. These conditions force contractors to deliver small batches of materials, which increases delivery and transportation costs. In addition, the bad conditions of some remote roads or the non-existence of roads at some stages make it difficult for all project parties to access the project site.

The pilot study revealed that SEC's supervisors do not use standard forms to write down notes during the inspection of construction sites. They primarily use mobile phones for communication and digital cameras to take photos of the project's progress. Supervision teams use email to communicate with the director of the regional office. Branch managers are not authorized to undertake decisions regarding a specific site's queries and decisions are left entirely to the director of the regional office. This substantially prolongs the decision-making period.

The pilot study results were used to design the primary study's questionnaire. The questionnaire is divided into two sections. The first section asks participants about the type of electronic or traditional management systems and tools presently used and who uses them. It also asks about the frequency of the site's queries - extracted from the projects' archive - and how badly these queries affect a project's performance and process. Section two asks about the CPMS that they recommend to manage remote construction projects. They were asked how much these systems would help in improving management practices and sorting out construction problems; these problems were extracted from the pilot study, including the projects' archive. It asks about potential barriers and how much these barriers would hinder implementation of CPMS. The targeted population consisted of contractors and SEC's supervisors/ engineers located in the four regions of KSA. This targeting method provides feedback from the two major project's parties, which would increase the applicability of the proposed CPMS to both of them. In 2009, one-hundred questionnaire forms were sent out randomly. Twenty five supervisors/ engineers and two contractors responded representing $27 \%$ of the targeted population. The majority of respondents were SEC staff so results expressed the views of SEC staff rather than the contractors.

The primary survey revealed that CPMS and tools are of little use to contractors and supervisors. Most of the respondents $70 \%$ to $89 \%$ ) said they use traditional communication systems and tools such as fax machines, mobile phones, site visits, weekly/monthly reports, and weekly/monthly meetings to manage jobs and communicate between the remote project site and the supervision office. They do not use mobile systems and tools apart from mobile phones, which are used by $93 \%$ of the respondents. None of the respondents uses web cams or construction robots on site. The WPMS is not used and e-mail services were used by only $67 \%$. Respondents indicated that electronic communications and management systems are widely unused among project team members. Around one-third of the respondents said that queries take four to six days to be sorted out during finishing, concrete, insulation, openings, mechanical, and electrical work stages. $33 \%$ to $41 \%$ said that queries during the mechanical and telecommunications/computers work stages take one to two weeks to be sorted out. Respondents agreed that the delay in sorting out queries negatively affects project performance - represented by cost, time, scope, and quality criteria - and the project process. Arranged from greatest to least, the most negative impacts are in regard to the delay in sorting out the following queries (see table 1 ):

- Mistakes in construction works

- Poor quality of construction work (project performance only)

- Selection of unskilled workers

- Equipment shortages

- Unavailability of materials

- Low productivity of workers

- Changes to specifications/specified materials (project process only) - Ineffective planning and scheduling of the project by the contractor

- Breakdown of site equipment (project performance only)

With regards to the potential use of CPMS tools, $82 \%$ of respondents recommended use of e-mail services. 74\% recommended use of mobile tools, $40 \%$ to $48 \%$ recommend use of walkie-talkies, fax, and web monitoring cameras, $22 \%$ to $30 \%$ recommend use of personal digital assistants and tablet computers, and 33\% recommend use of WPMS. Respondents said a CPMS would be especially helpful in sorting out the following construction problems: mistakes in construction work, delays in the project timetable, changes to the project's scope, changes to the specifications/specified materials, and increases in the costs of materials during construction (see table 2).

They said that the barriers that hinder the implementation of advanced electronic management and communications systems in SEC are primarily the management system (i.e., the organizational structure and practices); concerns over technical issues such as cost, 
maintenance, and support; difficulty in making changes to the organization's structure, internal influences, external pressures; and the level of staff IT skills (see Fig. 1).

\section{Discussion}

The findings of this research are discussed emphasizing the potential benefits of CPMS to SEC and the barriers that limit the applicability of CPMS to SEC's construction project management; special emphasis is given to how these barriers can be overcome. This study suggests that the construction department at SEC experiences a number of unique problems. Other researchers such as Deng et al. (2001), Kestle and London (2002, 2003), Kestle (2009) and McAnulty and Baroudi (2010) report similar problems. These problems can be categorized as follows:

\section{A. Human Resources:}

SEC has a staff shortage so employees are incapable of doing all required site visits. This has negative implications for the project since some uncommitted contractors seize this opportunity, make changes to construction plans, and hire unskilled workers. There is a lack of security and shortage in skilled workers. Government authorities are not able to visit the site frequently due to remoteness of the projects and inaccessible roads. The impact of the harsh working conditions on the productivity of SEC's supervisors has been briefly outlined in this study but the research did not inspect its impact on the productivity of the remote site's personnel.

Table 1. The degree of impact of the delay in sorting out remote site queries/ problems on the project process and performance (Column number two scale: 1, does not affect to 3, heavily affects. Column number three scale: 1 positive, 0 neutral, -1 negative)

\begin{tabular}{|c|c|c|}
\hline Type of queries/ problems & $\begin{array}{l}\text { Level of negative impact } \\
\text { of the delay on project } \\
\text { process (impact level } 1 \\
\text { to 3) }\end{array}$ & $\begin{array}{l}\text { Mean value of the negative } \\
\text { impact of the delay on } \\
\text { project performance } \\
\text { (represented by cost, } \\
\text { quality, scope, and time } \\
\text { criterions) } \\
\end{array}$ \\
\hline Mistakes in construction works & 2.63 & -0.48 \\
\hline Poor quality of construction works & 2.62 & -0.24 \\
\hline $\begin{array}{l}\text { The selection of unskilled workers by the contractor to } \\
\text { work on site }\end{array}$ & 2.54 & -0.44 \\
\hline Shortage in site equipment & 2.54 & -0.39 \\
\hline Unavailability of materials & 2.52 & -0.46 \\
\hline Low productivity of the workers & 2.48 & -0.49 \\
\hline Changes to specifications/ specified materials & 2.44 & -0.23 \\
\hline $\begin{array}{l}\text { Ineffective planning and scheduling of the project by the } \\
\text { contractor }\end{array}$ & 2.42 & -0.39 \\
\hline $\begin{array}{l}\text { Improper construction methods implemented by the } \\
\text { contractor }\end{array}$ & 2.38 & -0.32 \\
\hline $\begin{array}{l}\text { Problems related to the transportation of materials to the } \\
\text { site }\end{array}$ & 2.3 & -0.36 \\
\hline $\begin{array}{l}\text { Delay in the approval of contractor submissions by the } \\
\text { SEC engineers }\end{array}$ & 2.26 & -0.25 \\
\hline $\begin{array}{l}\text { The increase in materials' cost during the building's } \\
\text { construction }\end{array}$ & 2.22 & -0.27 \\
\hline Change of the project's scope by the contractor & 2.15 & -0.19 \\
\hline $\begin{array}{l}\text { Unavailability of SEC engineers on the remote project's } \\
\text { site due to their workload }\end{array}$ & 2.15 & -0.34 \\
\hline Delay in the project timetable & 2.11 & -0.3 \\
\hline $\begin{array}{l}\text { SEC tendering system that obligates the choice of the } \\
\text { lowest bidding value }\end{array}$ & 2.08 & -0.19 \\
\hline Inadequate equipment used & 1.96 & -0.29 \\
\hline Delay in conducting of the field survey by the contractor & 1.92 & -0.29 \\
\hline Unavailability of SEC engineers during sample testing & 1.88 & -0.35 \\
\hline Personnel safety issues & 1.85 & -0.06 \\
\hline Breakdown of equipment on site & 1.81 & -0.42 \\
\hline
\end{tabular}


Table 2. Level of help that the advanced technology would provide to sort out construction problems/ queries

\begin{tabular}{|c|c|c|c|c|c|c|}
\hline Issues to be sorted out & $\begin{array}{c}\text { Do } \\
\text { not } \\
\text { know } \\
(\%)\end{array}$ & $\begin{array}{l}\text { Not at } \\
\text { all (\%) }\end{array}$ & $\begin{array}{l}\text { Someho } \\
\text { w (\%) }\end{array}$ & $\begin{array}{l}\text { Neutral } \\
(\%)\end{array}$ & $\begin{array}{l}\text { Helpful } \\
(\%)\end{array}$ & $\begin{array}{c}\text { Very } \\
\text { Helpful } \\
(\%)\end{array}$ \\
\hline Mistakes in construction work & 0 & 0 & 11 & 15 & 11 & 60 \\
\hline Delay in the project timetable & 0 & 11 & 4 & 15 & 18 & 48 \\
\hline Change of the project's scope by the contractor & 11 & 22 & 11 & 4 & 19 & 26 \\
\hline Personnel Safety issues & 0 & 19 & 11 & 18 & 14 & 34 \\
\hline Changes to the specifications/ specified materials & 4 & 22 & 4 & 15 & 22 & 30 \\
\hline Poor quality of construction works & 0 & 15 & 4 & 15 & 26 & 37 \\
\hline $\begin{array}{l}\text { The increase in materials' cost during the building's } \\
\text { construction }\end{array}$ & 7 & 30 & 15 & 7 & 0 & 30 \\
\hline $\begin{array}{l}\text { The selection of unskilled workers by the contractor to } \\
\text { work on site }\end{array}$ & 7 & 15 & 11 & 19 & 15 & 26 \\
\hline Low productivity of the contractors' workers & 4 & 18 & 15 & 7 & 22 & 26 \\
\hline Unavailability of materials & 4 & 11 & 4 & 22 & 11 & 33 \\
\hline $\begin{array}{l}\text { Problems related to the transportation of materials to } \\
\text { the site }\end{array}$ & 4 & 11 & 8 & 22 & 18 & 30 \\
\hline $\begin{array}{l}\text { Ineffective planning and scheduling of the project by } \\
\text { the contractor }\end{array}$ & 4 & 4 & 22 & 15 & 18 & 30 \\
\hline $\begin{array}{l}\text { Unavailability of SEC engineers on the remote project } \\
\text { site due to their workload }\end{array}$ & 7 & 4 & 7 & 12 & 15 & 44 \\
\hline $\begin{array}{l}\text { Delay in the approval of contractor submissions by the } \\
\text { SEC engineers }\end{array}$ & 7 & 19 & 7 & 19 & 7 & 30 \\
\hline Shortage in site equipment & 7 & 19 & 18 & 8 & 18 & 15 \\
\hline $\begin{array}{l}\text { Delay in conducting of the field survey by the } \\
\text { contractor }\end{array}$ & 7 & 26 & 7 & 22 & 11 & 19 \\
\hline $\begin{array}{l}\text { SEC tendering system that obligates the choice of the } \\
\text { lowest bidding value }\end{array}$ & 22 & 22 & 7 & 15 & 8 & 15 \\
\hline Unavailability of SEC engineers during sample testing & 4 & 14 & 11 & 12 & 22 & 26 \\
\hline Breakdown of one of the site equipment & 11 & 4 & 18 & 11 & 19 & 26 \\
\hline $\begin{array}{l}\text { Improper construction methods implemented by the } \\
\text { contractor }\end{array}$ & 4 & 11 & 7 & 7 & 30 & 30 \\
\hline Inadequate equipment used & 7 & 11 & 7 & 19 & 26 & 15 \\
\hline
\end{tabular}

Note: sample size 27, missing or N/A values are not shown in this table.

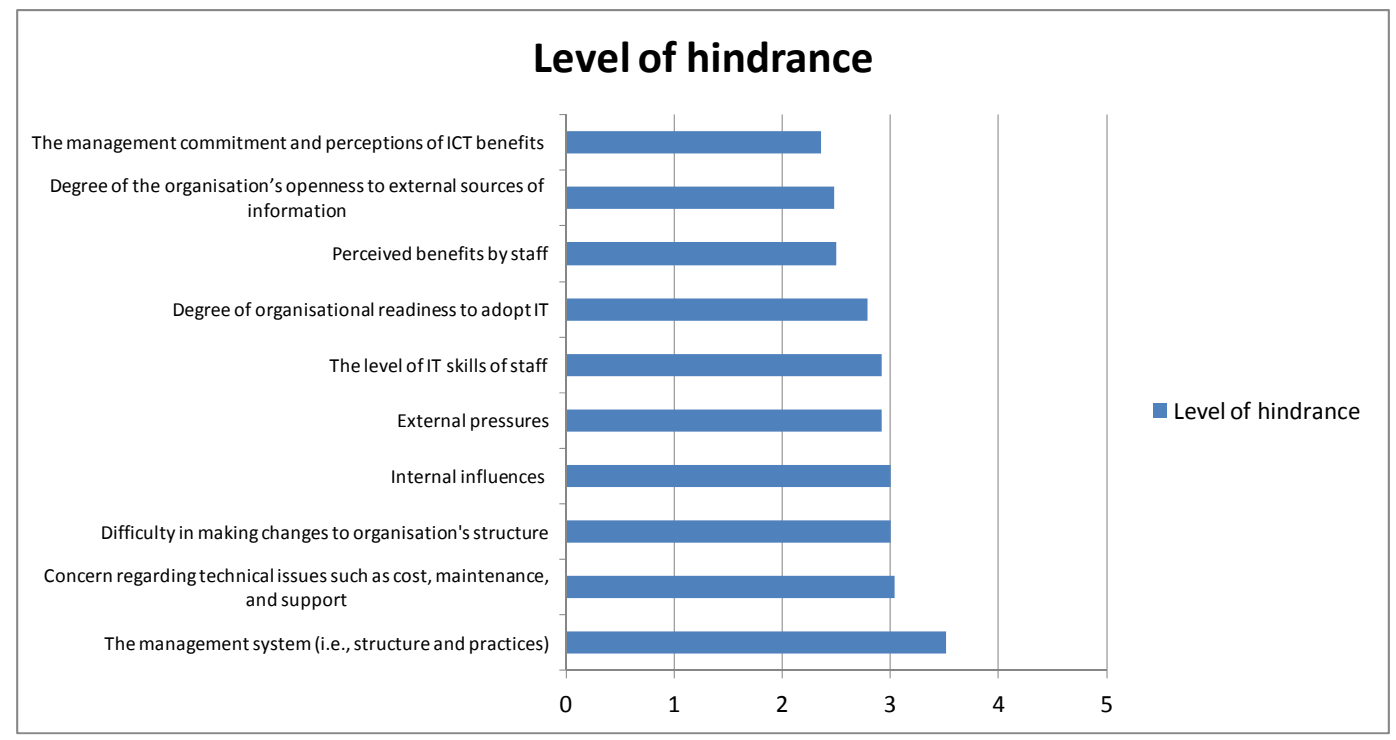

Fig. 1. Barriers that hinder the implementation of advanced electronic management and Communications systems in SEC. Scale: 1 does not hinder to 5 highly hinders 


\section{B. Cost, time, scope, and quality management:}

There is serious delay in sorting out a number of project queries and problems; these have a bad effect on the project's performance and process. Delays in decisionmaking, loose control, and infrequent visits to the remote site result in wasted time, excessive costs, unfocused scope, and poor construction quality.

\section{Procurement and risk Management:}

There is a frequent shortage of materials. This undoubtedly shows that procurement and supply of materials is not accurately planned by the SEC or its contractors. Contractors are reluctant to undertake remote projects due to unpredictable increases in the cost of the labor, materials, transportation. Delivery of materials and equipment is constrained by road/highway regulations and bad conditions of some remote roads. With traditional methods of running a remote project by both sides (SEC and the contractors), projects have much higher risk margins than ordinary projects. This results from an ad hoc approach and both sides do not accurately plan projects.

\section{Infrastructure and communications:}

Land ownership in some remote areas is not definite or known; legal disputes are likely to occur. There is a lack of or no infrastructure such as services, materials, and equipment. The survey demonstrates that contractors and SEC supervisors still use traditional communications and management tools and that CPMS is little used by project team members. Decisions are made autocratically since they are made solely by the director of the regional office. It is clear that SEC project managers are not able to control and coordinate integration of a project's aspects and the typical management style is non-standard, fragmented, and loose. Communications problems may take place even with the installation of any prospective CPMS. This is due to a number of potential barriers related to the project, SEC, and the CPMS itself. The top barriers include CPMS costs, maintenance and support, the management system, organizational readiness to change, and the IT skill levels of staff (Chan et al., 2004; Nitithamyong and Skibniewski, 2004; Villeneuve et al., 2003; Walker et al., 2005; Yang et al., 2007). Traditional management practices are also an obstacle of CPMS full utilization.

\section{Conclusions}

The study demonstrated that CPMS tools would help SEC in managing remote construction projects in KSA and overcome the present construction problems. It would support SEC's management activities, particularly during the construction stages that witness long delays in providing feedback to the construction enquiries. CPMS can be used to provide fast feedback to the site personnel regarding the most problematic construction problems (see Table 1 and 2) such as these related to the monitoring of the construction process, quality of work, procurement of materials and productivity levels. In specific CPMS can help regarding the following project management aspects:

\section{A. Human Resources:}

To monitor closely the contractors/ sub-contractors and site personnel activities and construction process, performance and outcomes. Thus any illegal changes to construction plans would be detected. Also, it would be used to substantially improve the site's security. The government authorities can be provided with regular updates about the progress of the construction process supported with captured photos and video shots.

\section{B. Cost, time, scope, and quality management:}

CPMS would help SEC eliminating some causes of potential delays. SEC would be capable to make fast decision making and control closely and more frequently the construction activities,

\section{Procurement and risk Management:}

CPMS would help SEC's supervisors to monitor the Procurement, supply and consumption of construction materials. During the construction stage, SEC would be capable to undertake precise daily control and follow-up procedures regarding issues such as remote examination of work quality, monitoring productivity of site workers, and calculation of material consumption rates. SEC would be capable to estimate the risk margins and to adjust their project management methods to minimize the risk for the future projects. The problem of managing remote construction sites exists at different levels. These problems should be examined to enable SEC to grasp fully the potential of CPMS. This researcher recommends these actions at the following levels:

- Project level: Design and pre-planning of site activities such as supply and human resources should consider the environment and project variables mentioned above. Flexible decision-making mechanisms should be created and tested. Present project management practices should be redesigned and remote manager abilities should be improved. SEC should consider short and long-term partnering with contractors. This includes linking systems and sharing information and management tools. This would enhance knowledge integration and help to foster innovative ideas that dramatically improve projects (Barlow, 2000). Some problems seem to be generated during other stages of the project; some are expected such as recruitment of skilled workers, transportation of materials, and other unforeseen problems such as possible shortages in manpower and breakdown of equipment. These should be studied and resolved at the initial planning stages of the project. Emergency scenarios should be established at the early stages of the project to deal with unexpected issues. Prior to any engagement, SEC should draw the contractor's attention to the unique problems and foreseeable issues associated with the construction of remote projects.

- Staff level: Proper plans should be adopted for SEC's staff and contractor training; staff should be informed about the benefits and advantages of new CPMS systems. Managers should be trained on how to manage remote sites virtually.

- CPMS level: Design of the new CPMS should consider the negative impacts of the project and environment variables on project performance and processes. This study suggests that CPMS should be designed to offer help on two levels: a) vertically during the project life from the design and planning stages through the tendering stage until the occupation/use stage and b) horizontally by integrating all the project parties' systems, knowledge, and information along the supply chain. This researcher understands the limitations of the case study presented in 
this paper with regard to the number of participants. However, this could be used as foundation work for future research, which investigates in-depth the problems and possible IT solutions for other remote projects in KSA.

\section{References}

Ahuja, V., Yang, J. and Shankar, R. (2009). Benefits of collaborative ICT adoption for building project management, Construction Innovation: Information, Process, Management, 9(3), 323-40.

Al Omairi, S., Sidawi, B. (2010). The Potential Use of Web-Based Project Management Systems to Manage Construction Projects by the Royal Commission of Jubail. 1st International Graduate Research Symposium on the Built Environment, Middle East Technical University, Ankara, Turkey, 15-16 October 2010. METU: Turkey.

Alshawi, M., Goulding, J., Khosrowshahi, F., Lou, E. and Underwood, J. (2009). How strategic is IT investment in the construction industry?, A UK Perspective, Modern Built Environment -Knowledge Transfer Networks, Intelligent Buildings Index, January, 1-3.

Alshawi, M, Ingirige, B. (2003). Web-enabled project management: an emerging paradigm in construction. Automation in Construction, 12, 349-364.

Barlow, J. (2000), Innovation and learning in complex construction projects, Research Policy, 29, 973-989.

Becerik, B. (2005). Critical Enhancements for Improving Adoption of OPM Technologies. Harvard Graduate School of Design, Barrie Award Winning Reports, PMI Educational Foundation Funded.

Bowden, S. (2005). Application of mobile IT in construction. PhD Dissertation, University of Loughborough, Department of Civil and Building Engineering

Chan, A. P. C., Scott, D., and Chan, A. P. L. 2004. Factors Affecting the Success of a Construction Project. Journal of construction Engineering and Management, 130(1), 153-155.

Charoenngam, C., Ogunlana, S. O., Kang, N. F., and Dey Prasanta, K. (2004). Re-engineering construction communication in distance management framework [online] Available at: http:www.construct-it.org.uk/ .../Web\%20Enabled\%20Project\%20Management.pdf

Davidson, C. H. and Moshini, R. (1990). Effects of Organisational Variables upon Task Organisations' Performance in the Building Industry. Building Economics and Construction Management, 4, 17-22.

Deng, Z. M., Li, H., Tam, C. M., Shen, Q. P. and Love, P. E. D. (2001). An application of the Internet-based project management system. Automation in construction, 10, 239-246

Kestle, L and London, K. (2002). Towards the development of a conceptual design management model for remote sites. In C. Formoso and G. Ballard (Eds.), 10th Annual Conference on 'Lean Construction (IGLC-10), 309-322. Gramado: Federal University of Rio Grande Do Sul, 6-8 August,

Kestle, L. and London, K. (2003). Remote site design management -the application of case study methodology. In the proceedings of the Post Graduate Construction Research Conference, Melbourne. Australia

Kestle, L. (2009). Remote Site Design Management, $P h D$ thesis, University of Canterbury NZ.
Ko, C. H. (2011). Integration of Engineering, Project, and Production Management, Journal of Engineering, Project, and Production Management, 1(1), 1-2.

Leskinen, S. (2006). Mobile Solutions and the Construction Industry Is it a working combination? VTT publications. [online] Available at: http: www.vtt.fi/inf/pdf/publications/2006/P617.pdf

Leskinen, S. (2008). Mobile technology in the Finnish construction industry - present problems and future challenges. 21st Bled eConference eCollaboration: Overcoming Boundaries through Multi-Channel Interaction, June 15 - 18, 2008. Bled: Slovenia.

Morse, J. M. (Editor), (1991). Qualitative health research. Newbury Park, Calif.: Sage.

McAnulty, S., Baroudi, B., (2010). Construction Challenges in Remote Australian Locations, Association of Researchers in Construction Management (ARCOM) Conference, Leeds, United Kingdom, September.

Nitithamyong, P. and Skibniewski, M. J. (2004). Webbased construction project management systems: how to make them successful?. Automation in Construction, 13, 491-506.

Nitithamyong, P. t. and Skibniewski, J. M. (2006). Success/Failure Factors and Performance Measures of Web-based Construction Project Management Systems: Professionals' Viewpoint. Journal of Construction Engineering and Management ASCE, 80-87.

Nuria, F. M. (2005). Life cycle document management system for construction. $\mathrm{PhD}$ thesis. Universitat Politechica De Catalunya. [online] Available at: http://www.tesisenxarxa.net/TESIS_UPC/AVAILAB LE/TDX-0518105-155912/

OppenheimA. N., (1992). Questionnaire design, interviewing and attitude measurement. London: Pinter

Pena-mora, F., Vadhavkar, S., Aziz, Z. (2009). Technology strategies for globally dispersed construction teams. Journal of Information Technology in Construction. http://www.itcon.org/200 $9 / 08$

Stewart, R.A. and Mohamed, S. (2004). Evaluating webbased project information management in construction: capturing the long-term value creation process. Automation in Construction, 13(4), 469-479.

Shepard, J., Robert W. G. (2003). Sociology and You. Ohio: Glencoe McGraw-Hill

Stichting, b. (2000). De bouw moet om, op weg naar feilloos bouwen (in Dutch), Rotterdam.

Thomas, S., Palaneeswaran, E. and Kumaraswamy, M. M. (2003). Web-based Centralized Multiclient Cooperative Contractor Registration System, Journal of computing in civil engineering, 28-37.

Thorpe, D. (2000). E-projects in action - the online remote construction management research project. CIIA Fifth Annual Conference: Innovation in Construction, Construction Industry Institute, Australia.

Turban, E., Mclean, E. and Wetherbe, J. (1996). Information Technology for Management: Improving Quality and Productivity, John Wiley and Sons, New York, NY.

Uden, L., Naaranoja, M. (2007). The development of online trust among construction teams in Finland, ITCON. \{online] Available at http://itcon.org/ 2007/21/ 
Vadhavkar, S. and Pena-Mora, F. (2002). Empirical Studies of the Team Interaction Space: Designing and Managing the Environments for Globally Dispersed Teams. International Workshop on the Role of Empirical Studies in Understanding and Supporting Engineering Design Work, NIST, Gaithersburg, 2000. MD: USA.

Vanita, A., Jay, Y., and Ravi, S. (2010). IT-enhanced communication protocols for building project management. Engineering, Construction and Architectural Management Journal, 17(2), 159-79.

Villeneuve, C. E., and Fayek, A. R. (2003). Construction project web sites: design and implementation. Cost Engineering, AACE, 45(1): 26-31.

Walker, D. V., Peansupap, H.T. (2005). Factor enabling information and information technology diffusion and actual implementation in construction organizations, ITCON. 10, 193-218.

Wamelink, J.W.F., Stoffele, M., and Van Der Aalst W.M.P. (2002). Workflow management in construction; Opportunities for the future. International Council for Research and Innovation in Building and Construction. CIB w78 conference, Aarhus School of Architecture, 12-14 June 2002. CIB: Denmark.

Yang, J., Ahuja, V. and Shankar, R. (2007). Managing Building Projects through Enhanced Communication - An ICT Based Strategy for Small and Medium Enterprises, CIB World Building Congress 2007, 2334-2356. CIB: South Africa

Yin, R. K. (2009). Case Study Research: Design and Methods. 4th Edition. SAGE Publications. California.

Zou, P. and Roslan, B. (2005). Different perspectives towards using web-based project management systems in construction: large enterprises versus small- and medium-sized enterprises, Architectural engineering and design management, 1(2), 127-143.

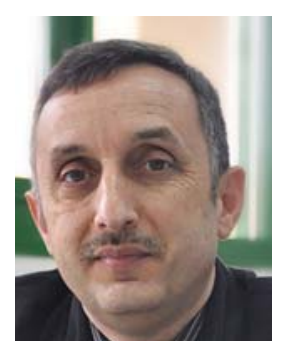

Bhzad Sidawi is an assistant professor, department of Architecture, College of Architecture and Planning at University of Dammam. He is a member of AHRA and SES. His research interests include innovation and architectural design, management of remote construction projects, on-going finance of low-income's property's owners, e-business applications in the construction industry, diabetes and building syndrome. 